\title{
Ionic Conductivity Studies on Nano CuO Dispersed Phase-Separated Polymer Electrolytes
}

\author{
D. RAVINDRAN ${ }^{*}$ and P. VICKRAMAN ${ }^{2}$ \\ ${ }^{1}$ Department of Physics, Thiagarajar College of Engineering, Madurai, India \\ ${ }^{2}$ Department of Physics, Gandhigram Rural University, Dindigul, India \\ ravi4xyz@gmail.com
}

Received 2 January 2015 / Accepted 21 January 2015

\begin{abstract}
Polyvinyl chloride (PVC) and polyethylene glycol (PEG) blend based polymer electrolytes were prepared with lithium perchlorate $\left(\mathrm{LiClO}_{4}\right)$ as dopant salt. The nano-sized $\mathrm{CuO}$ particles were synthesized through sol-gel method and incorporated as filler. The electrolyte films were subjected to AC impedance analysis. The analysis reveals the strong influence of $\mathrm{CuO}$ particles on the conductivity profile. The film with $2 \mathrm{wt} \%$ of $\mathrm{CuO}$ exhibits higher conductivity of $4.013 \times 10^{-6}$ $\mathrm{S} / \mathrm{cm}$ at room temperature. The thermal stability of the membrane was ascertained through TGA analysis. The morphological study reveals the formation of dual-phase, an electrolyte rich-phase and polymer rich-phase.
\end{abstract}

Keywords: Nano $\mathrm{CuO}$ filler, Polymer electrolytes, Ionic conductivity, TGA analysis, SEM analysis

\section{Introduction}

Solid polymer electrolytes are emerging as the most promising electrolyte materials for applications in all solid-state lithium batteries, super capacitors, fuel cells, dye sensitized solar cells etc., It has many advantages over its counterpart liquid electrolytes such as mechanical stability and processing flexibility, but their ionic conductivity at room temperature is too low, which limited their practical application. In order to improve the conductivity different strategies have been attempted, such as the blending of polymers ${ }^{1}$, plasticization $^{2}$, incorporation of nano fillers ${ }^{3}$ etc. The addition of low molecular weight plasticizers such as ethylene carbonate (EC), propylene carbonate (PC), poly ethylene glycol (PEG) etc. to the polymer-salt system has been regarded as an efficient method. However the inclusion of plasticizers enhances the conductivity by reducing mechanical properties. The mechanical strength can be improved by blending with poly (vinyl chloride) PVC which provides a rigid frame work due to its poor solubility in the liquid electrolyte ${ }^{4}$. The dispersion of nano particles to the polymer electrolyte enhances the transport properties, mechanical, electrochemical properties and increases the absorption level of electrolyte solution. The nanocomposite polymer electrolytes (CPE) can offer improved electrolyte/ electrode compatibilities and safety hazards ${ }^{5}$. In the present work, we have synthesized the 
nano $\mathrm{CuO}$ particles and dispersed as filler material in the PVC-PEG blend matrix. The effect of filler particles on the conductivity profile was analyzed through AC impedance studies. The thermal stability of the films was ascertained through TGA analysis. The influence of filler on the surface morphology was examined through SEM analysis.

\section{Experimental}

The cupric oxide $(\mathrm{CuO})$ nanoparticles were synthesized through sol-gel method. The $0.1 \mathrm{M}$ aqueous solution of $\mathrm{Cu}\left(\mathrm{NO}_{3}\right)_{2} \cdot 2 \mathrm{H}_{2} \mathrm{O}$ was prepared in a glass beaker and $0.9 \mathrm{M} \mathrm{NaOH}$ solution was added slowly under constant stirring at room temperature. The $\mathrm{pH}$ value was maintained at 13 . The resulting blue gel was washed several times with de-ionized water. The precipitate was filtered dried in air at $60{ }^{\circ} \mathrm{C}$ for $12 \mathrm{~h}$. The dried powder was annealed at $350{ }^{\circ} \mathrm{C}$. Poly vinyl chloride (PVC) with average $\mathrm{M}_{\mathrm{w}} \sim 62,000$ were purchased from SigmaAldrich and poly ethylene glycol (PEG) with average $\mathrm{M}_{\mathrm{w}} \sim 200$ from S.D Fine chemicals, India. The lithium perchlorate $\left(\mathrm{LiClO}_{4}\right)$ was procured from Sigma-Aldrich was dried at $110{ }^{\circ} \mathrm{C}$ under vacuum for at least $48 \mathrm{~h}$ prior to use. The appropriate $\mathrm{wt} \%$ of salt was dissolved in anhydrous tetrahydrfuran and other constituents were added and continuously stirred for $18-20 \mathrm{~h}$, the resulting viscous solution was cast on glass plates. The crystalline nature of the electrolyte films was investigated using JEOL, JDX $8030 \mathrm{x}$-ray diffractometer. The impedance measurements were carried out using a computer-controlled LCR HiTESTER (3532-50 Hioki, Japan) in the frequency range $50 \mathrm{~Hz}-100 \mathrm{KHz}$. The ionic conductivity measurements were carried out by sandwiching the composite gel polymer electrolyte between two stainless steel (SS) electrodes. Thermal analysis was studied using Perkin Elmer (Pyres diamond thermogravimetry/differential thermal analysis, TG/DTA) at a heating rate of $10{ }^{\circ} \mathrm{C}$ per minute from $30{ }^{\circ} \mathrm{C}$ to $550{ }^{\circ} \mathrm{C}$. The surface morphology of the samples was examined by JEOL, JSM-840A scanning electron microscope.

\section{Results and Discussion $X R D$ analysis}

Figure 1 shows the XRD pattern of $\mathrm{CuO}$ nanoparticles, the two prominent peaks are observed at $2 \theta=35.5^{\circ}$ and $38.7^{\circ}$. The observed peaks matches well with the monoclinic phase of $\mathrm{CuO}$ bulk crystals and well consistent with JCPDS card (card no: 048-1548). No impurity peak related to any other phases of $\mathrm{Cu}$ like $\mathrm{Cu}(\mathrm{OH})_{2}, \mathrm{Cu}_{2} \mathrm{O}$ or $\mathrm{Cu}$ are seen in the diffractogram. The obtained pattern coincides with earlier reported results ${ }^{6}$. The average size of the particles determined using the Scherrer relation is $32 \mathrm{~nm}$.

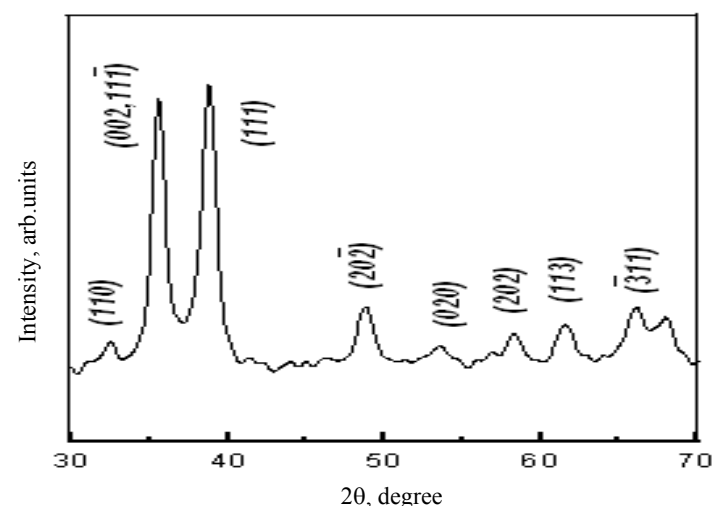

Figure 1. XRD pattern of $\mathrm{CuO}$ nanoparticles 


\section{Conductivity analysis}

The conductivity was determined using the relation $\sigma=l / \mathrm{R}_{\mathrm{b}}\left(\pi \mathrm{r}^{2}\right)$ where $l$ is the thickness of the electrolyte film, $r$ is the radius of the membrane and $R_{b}$ is the bulk resistance obtained from the plots of real impedance $Z_{r}$ against imaginary impedance $Z_{i}$. The film with composition (PVC-PEG-PC-LiClO $4-\mathrm{CuO})=(23-15-50-10-2)$ exhibits higher conductivity of $4.013 \times 10^{-6} \mathrm{~S} / \mathrm{cm}$ at room temperature The variation ionic conductivity at room temperature with respect to the content of nano $\mathrm{CuO}$ filler is shown in Figure 2. The conductivity is not a linear function of filler concentration. The conductivity further features two maxima one occurring at $0.5 \mathrm{wt} \%$ and the other at $2 \mathrm{wt} \%$ of filler. Such two maxima behavior has been reported in gel polymer electrolyte composites ${ }^{7}$. The first conductivity maximum is possibly due to the dissociation ion aggregates / undissociated salt into free ions with the addition of filler particles. The decrease in conductivity after the first maxima is related with the formation of ion pairs and bigger-sized ion clusters due to reassociation of free ions. The second conductivity maximum is attributed to the formation of a conducting interfacial space-charge layer at the filler/polymer interface, which promotes the ion transport. But beyond this optimum level, the addition of filler increases the viscosity of the system which hindered the ion mobility.

\section{TGA analysis}

The thermo gravimetric analysis curve of the sample with $2 \mathrm{wt} \%$ filler which exhibits higher conductivity is shown in Figure 3. The steep degradation curve shows three distinct regions where the film degrades gradually up to $150{ }^{\circ} \mathrm{C}$ with $20 \%$ weight loss. This could be due to the evaporation of moisture absorbed by the sample during loading and the evaporation of residual solvent. The sample suffers a sudden weight loss from $140{ }^{\circ} \mathrm{C}$ to $220{ }^{\circ} \mathrm{C}$. Further the sample suffers nearly $85 \%$ from $245^{\circ} \mathrm{C}$ to $290{ }^{\circ} \mathrm{C}$. The TGA curve is consistent with the earlier reported result in PVC-PEG-TiO system $^{3}$.

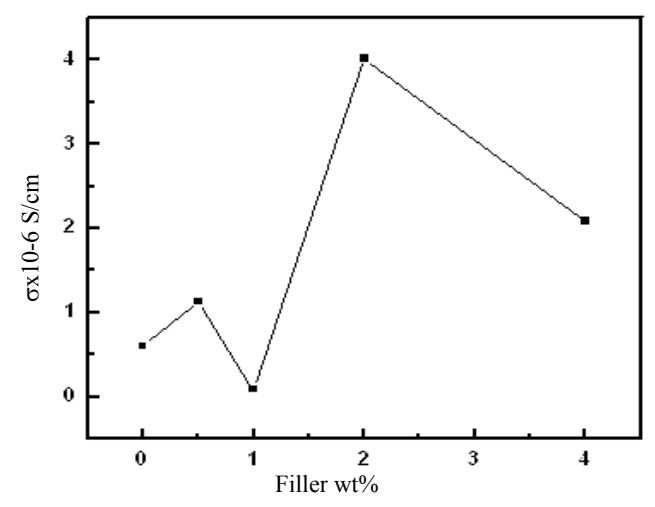

Figure 2. Variation of conductivity with filler $(\mathrm{wt} \%)$

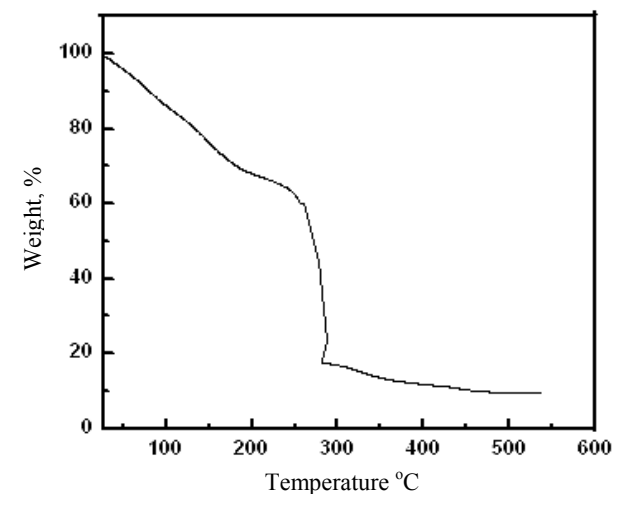

Figure 3. TGA curve

\section{SEM analysis}

Figure 4 shows the SEM images of film without filler, with $1 \mathrm{wt} \%$ filler and with $2 \mathrm{wt} \%$ of filler. The addition of filler drastically changes the morphology of the electrolyte membranes. The SEM images of film exhibits interconnected network of pores. The pores are indicative of the occurrence of phase separation in the electrolytes, which are indeed necessary for the transportation $\mathrm{Li}^{+}$ions between the electrodes ${ }^{8}$. The phase separation in the 
PVC based polymer electrolyte originates from the immiscibility of PVC with the liquid electrolyte. These pores are the sites where the liquid electrolyte solutions have been trapped and the network-like pore walls correspond to the PVC rich phase. The addition of $1 \mathrm{wt} \%$ of filler results in the disruption the network structure and a decrease in porosity o $f$ the membrane. The film with $2 \mathrm{wt} \%$ of filler shows the development pore structure with better connectivity which aids faster ion motion. Among the two images of films with $1 \mathrm{wt} \%$ and 2 $\mathrm{wt} \%$ filler, the latter exhibits larger pores hence it contains higher plasticizer- rich phase and lower PVC-rich phase that leads to higher conductivity. The PVC-rich phase acts as a mechanical support and the plasticizer-rich phase inter-connected through a labyrinth of channels for ionic transport.
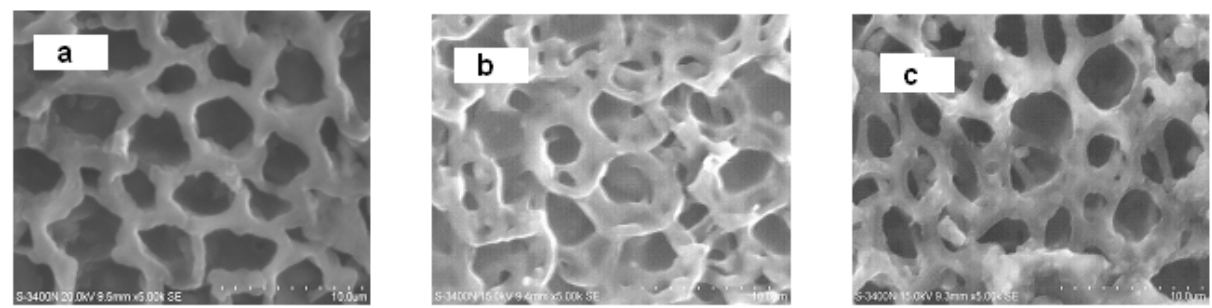

Figure 4. SEM images of the film a. $0 \mathrm{wt} \%$ filler, b. with $1 \mathrm{wt} \%$ of filler, c. with $2 \mathrm{wt} \%$ of filler

\section{Conclusion}

The influence sol-gel synthesized nano $\mathrm{CuO}$ particles on the conductivity behavior PVCPEG blend polymer electrolytes are studied. The conductivity analysis depicts the strong influence of filler particles on the conductivity profile and the film with $2 \mathrm{wt} \%$ filler exhibits higher conductivity. The thermal stability of the membrane was ascertained through TGA analysis. The SEM analysis supports result obtained in the conductivity studies.

\section{References}

1. Sivakumar M, Subadevi R, Rajendran S, Wu H C and Wu N L, Eur Polym J., 2007, 43(10), 4466-4473; DOI:10.1016/j.eurpolymj.2007.08.001

2. Hee-jin Rhoo, Hee-Tak Kim, Jung-Ki Park and Taek-Sung Hwang, Electrochimca Acta, 1997, 42(10), 1571-1579; DOI:10.1016/S0013-4686(96)00318-0

3. Rajendran S, Ravi Shankar Babu and Renuka Devi K, Ionics, 2009, 15(1), 61-66; DOI:10.1007/s11581-008-0222-3

4. Rajendran S, Ramesh Prabhu and Usha Rani M, Int J Electrochem Sci., 2008, 3, 282-290.

5. Pradeep K. Varshney and Shikha Gupta, Ionics, 2011, 17(6), 479-483; DOI:10.1007/s11581-011-0563-1

6. Mallick P and Sahu S, Nanoscience and Nanotechnology, 2012, 2(3), 71-74; DOI:10.5923/j.nn.20120203.05

7. Pandey G P, Agarwal R C and Hashmi S A, J Power Sources, 2009, 190(2), 563-572; DOI:10.1016/j.jpowsour.2009.01.057

8. Vickraman P and Ravindran D, Ionics, 2011, 17, 565-571; DOI: 10.1007/s11581011-0577-8 